\title{
Analyzing the Basic Properties and Environmental Footprint Reduction Effects of Highly Sulfated Calcium Silicate Cement
}

\author{
Hyeon-Soo Kim ${ }^{1, *}$, Ik Kim ${ }^{2}$, , Wan-Hee Yang ${ }^{3}$, Soo-Young Moon ${ }^{1}$ and Ji-Young Lee ${ }^{1}$ \\ 1 Korea Institute of Civil Engineering and Building Technology (KICT), Goyang-si 10223, Korea; \\ symoon@kict.re.kr (S.-Y.M.); raumpl@kict.re.kr (J.-Y.L.) \\ 2 SMaRT-Eco Consulting Firm, Seoul 06338, Korea; kohung@smart-eco.co.kr \\ 3 R\&D CENTER, WITHMTECH Co., Ltd., Suwon-si 16367, Korea; dangchan74@empas.com \\ * Correspondence: hskim1@kict.re.kr
}

Citation: Kim, H.-S.; Kim, I.;

Yang, W.-H.; Moon, S.-Y.; Lee, J.-Y. Analyzing the Basic Properties and Environmental Footprint Reduction Effects of Highly Sulfated Calcium Silicate Cement. Sustainability 2021, 13, 7540. https://doi.org/10.3390/ su13147540

Academic Editor: Vasiliki Pachta

Received: 11 May 2021

Accepted: 25 June 2021

Published: 6 July 2021

Publisher's Note: MDPI stays neutral with regard to jurisdictional claims in published maps and institutional affiliations.

Copyright: (c) 2021 by the authors. Licensee MDPI, Basel, Switzerland. This article is an open access article distributed under the terms and conditions of the Creative Commons Attribution (CC BY) license (https:// creativecommons.org/licenses/by/ $4.0 /)$.

\begin{abstract}
In South Korea, efforts to reduce carbon dioxide emissions and environmental impacts from the perspective of life cycle assessment (LCA) are important because of the implementation of zeroenergy building certification for public buildings and the promotion of net-zero policy. Therefore, it is critical to develop cement alternatives with low embodied energy and less environmental impact. In this study, the applicability of "highly sulfated calcium silicate cement (HSCSC)," an eco-friendly binder developed by our research team, was investigated. Its basic properties and environmental footprint reduction effects were examined in comparison with ordinary Portland cement (OPC) and Portland blast furnace slag cement (PBSC). The environmental impacts of the HSCSC were analyzed using the LCA method. The results confirmed that HSCSC can be considered an excellent alternative to conventional OPC or PBSC in certain areas as an eco-friendly binder that can reduce carbon dioxide emissions and environmental impacts. Moreover, compared to OPC and PBSC, the probability of HSCSC affecting the human body is extremely low. The results of this study may contribute to the development and practical use of cements that minimize climate impacts, as well as improve the efficacy of future research on embodied energy saving.
\end{abstract}

Keywords: highly sulfated calcium silicate cement; super sulfated cement; environmental footprint; embodied energy; ecological architecture

\section{Introduction}

Reducing carbon dioxide in response to climate change is a common task being performed worldwide. The South Korean government has formulated a roadmap for mandatory zero-energy building (ZEB) certification in June 2019 and made ZEB certification mandatory for public buildings with a total floor area of $1000 \mathrm{~m}^{2}$ or larger in 2020 . This scheme will be extended to private buildings by 2025 [1]. In addition, the Korean government has officially announced its net-zero policy goal in an effort to reduce net greenhouse gas emissions to zero by 2050 . This will be the impetus for spreading technologies as a response to climate change in the architectural sector along with the smart green deal policy, which has been recently promoted by the Korean government.

Thus far, the architectural sector has focused on reducing the use of fossil fuels in the operation stage to reduce carbon dioxide emissions. However, to achieve the net-zero policy goal, efforts to reduce the embodied energy generated during the collection and production of building materials are essential. Nevertheless, even in the case of ecological architecture that aims to minimize carbon dioxide emissions and environmental impacts over the life cycle, foundations or frames mostly use concrete, which requires high energy consumption during the production of materials. This is because of the difficulty in finding useful alternatives for the existing approach using concrete, when various factors, such as structural safety and economic efficiency, are comprehensively considered. Even when wooden structures are used in ecological architecture, ordinary Portland cement 
(OPC) concrete that uses OPC as a binder is mainly used for building foundations. Hence, developing a new binder in a more eco-friendly way that can reduce the embodied energy of concrete can be a useful alternative to finding a construction method that can replace concrete foundations.

There are eco-friendly binders that cause less carbon dioxide emissions than OPC, including magnesium phosphate cement (MPC), geopolymer, alkali-activated slag cement (AASC), and super sulfated cement (SSC) [2-9]. In general, it is difficult to use MPC, geopolymer, and AASC as alternatives to OPC because their price competitiveness is low, and their mass production is difficult. SSC is one of the most competitive alternatives to OPC considering carbon dioxide emission reduction, environmental impact minimization, availability, and economic efficiency.

POSCO, a representative steel company in South Korea, produced 24.23 million tons of steel byproducts in 2018, with blast furnace slag representing approximately half of them [10]. Huge quantities of blast furnace slag are generated every year, approximately equal to a quarter of the cement production for the Korean market. Therefore, in South Korea, SSC that uses blast furnace slag as the main component may be a more competitive alternative to OPC. Based on this concept, a highly sulfated calcium silicate cement (HSCSC), a type of SSC, was developed in this study as a more eco-friendly alternative to concrete binders. This study aims to evaluate the basic properties of HSCSC by comparing it with OPC and Portland blast furnace slag cement (PBSC), which are commonly used in South Korea. Further, this study attempts to evaluate its applicability through the quantitative analysis of its carbon dioxide emission and environmental impact reduction effects.

\section{Materials and Methods}

2.1. Properties of HSCSC

\subsubsection{General Properties of SSC}

As HSCSC is a type of SSC, its properties can be predicted by examining the general properties of SSC. SSC is a cement that uses the sulfate activation of slag, which is a byproduct of the steel industry. Sulfate activation of slag was first discovered by Hans Kühl in 1909 and then standardized in Germany, France, Belgium, and the United Kingdom [11]. It is considered that the SSC production increased as a substitute for OPC, which was in short supply after the Second World War. The SSC composition based on BS EN 15,743 [12] is shown in Table 1. In general, for alkaline activation, $80-85 \%$ granulated blast furnace slag and $10-15 \%$ calcium sulfate are used with less than 5\% OPC. SSC is an alternative that can significantly reduce carbon dioxide emissions compared to OPC because it mainly uses industrial byproducts, such as slag and calcium sulfate, with a small amount of OPC.

Table 1. Composition of SSC (percentage by weight).

\begin{tabular}{cccc}
\hline \multicolumn{2}{c}{ Main Constituents } & \multicolumn{2}{c}{ Additional Constituents } \\
\hline Granulate Blast furnace slag & Calcium sulfate & Portland cement clinker & Other \\
\hline S & Cs & K & A \\
$S \geq 75$ & $5 \leq$ Cs $\leq 20$ & $0 \leq \mathrm{K} \leq 5$ & $0 \leq \mathrm{A} \leq 5$ \\
\hline
\end{tabular}

The slag used for SSC is mainly activated by calcium sulfate. Calcium sulfate can be gypsum calcium sulfate dihydrate $\left(\mathrm{CaSO}_{4} \cdot 2 \mathrm{H}_{2} \mathrm{O}\right)$, hemihydrate $\left(\mathrm{CaSO}_{4} \cdot \frac{1}{2} \mathrm{H}_{2} \mathrm{O}\right)$, anhydrite (anhydrous calcium sulfate, $\mathrm{CaSO}_{4}$ ), or any mixture of the three. Gypsum and anhydrite are found naturally. Calcium sulfate is also available as a by-product of certain industrial processes [11]. When OPC is added to SSC, calcium hydroxide is generated as a result of hydration, thereby creating an alkaline environment that accelerates slag dissolution. The ions dissolved from the slag react with the calcium sulfate present in the mixture forming major products, such as ettringite and calcium silicate hydrates (C-S-H) [13-15].

$$
\mathrm{C}_{5} \mathrm{~S}_{3} \mathrm{~A}+\mathrm{CH}+3 \mathrm{CS}+34 \mathrm{H} \rightarrow \mathrm{C}_{6} \mathrm{AS}_{3} \mathrm{H}_{32}+3 \mathrm{CSH} .
$$


SSC typically emits small amounts of $\mathrm{CO}_{2}$ during its production process, releases low hydration heat during strength development, and exhibits excellent durability in harsh environments, such as seawater and sulfate groundwater [14]. In addition, SSC concrete has a higher long-term strength than OPC concrete despite its low initial strength development [16-19].

\subsubsection{Composition of HSCSC}

The HSCSC was fabricated in accordance with the composition of the SSC set by BS EN 15,743 (Table 1). Focusing on reducing carbon dioxide emissions and environmental impacts by using HSCSC as an alternative to climate change response policies that have been reinforced in South Korea, the amount of OPC was minimized, and a small amount of calcium hydroxide was used alternatively. Table 2 shows the composition of the HSCSC used in this study. Tables 3 and 4 list the properties of blast furnace slag, calcium sulfate, OPC, and calcium hydroxide, which are the constituents of HSCSC. The fineness of the blast furnace slag used for the production of PBSC generally ranges from 4000 to $4300 \mathrm{~cm}^{2} / \mathrm{g}$, whereas that of the slag used for the development of HSCSC is $6470 \mathrm{~cm}^{2} / \mathrm{g}$.

Table 2. Composition of HSCSC (percentage by weight).

\begin{tabular}{cccc}
\hline \multicolumn{2}{c}{ Main Constituents } & \multicolumn{2}{c}{ Additional Constituents } \\
\hline Granulate Blast furnace slag & Calcium sulfate & Portland cement & Other \\
\hline S & Cs & K & A \\
80 & 15 & 2 & 3 \\
\hline
\end{tabular}

Table 3. Physical properties of HSCSC constituents.

\begin{tabular}{cl}
\hline Category & \multicolumn{1}{c}{ Properties } \\
\hline Granulate Blast furnace slag & Density: $2.91 \mathrm{~g} / \mathrm{cm}^{3}$, Blain: $6471 \mathrm{~cm}^{2} / \mathrm{g}$ \\
Calcium sulfate & Density: $2.90 \mathrm{~g} / \mathrm{cm}^{3}$, Blain: $4344 \mathrm{~cm}^{2} / \mathrm{g}$ \\
Portland cement & Density: $3.15 \mathrm{~g} / \mathrm{cm}^{3}$, Blain: $3320 \mathrm{~cm}^{2} / \mathrm{g}$ \\
Calcium hydroxide & Density: $2.24 \mathrm{~g} / \mathrm{cm}^{3}$, Blain: $2778 \mathrm{~cm}^{2} / \mathrm{g}$ \\
\hline
\end{tabular}

Table 4. Chemical composition of HSCSC constituents.

\begin{tabular}{|c|c|c|c|c|c|c|c|}
\hline \multirow{3}{*}{$\begin{array}{c}\text { Category } \\
\text { Granulate Blast furnace slag }\end{array}$} & \multicolumn{7}{|c|}{ Chemical Composition } \\
\hline & $\mathrm{CaO}$ & $\mathrm{SiO}_{2}$ & $\mathrm{Al}_{2} \mathrm{O}_{3}$ & $\mathrm{Fe}_{2} \mathrm{O}_{3}$ & $\mathrm{MgO}$ & $\mathrm{SO}_{3}$ & $\mathrm{~K}_{2} \mathrm{O}$ \\
\hline & 39.22 & 34.1 & 14.94 & 0.55 & 6.84 & 2.2 & 0.61 \\
\hline \multirow{2}{*}{ Calcium sulfate } & $\mathrm{CaO}$ & $\mathrm{SiO}_{2}$ & $\mathrm{Al}_{2} \mathrm{O}_{3}$ & $\mathrm{Fe}_{2} \mathrm{O}_{3}$ & $\mathrm{SO}_{3}$ & & \\
\hline & 41.64 & 0.13 & 0.17 & 0.39 & 54.9 & & \\
\hline \multirow{2}{*}{ Portland cement } & $\mathrm{CaO}$ & $\mathrm{SiO}_{2}$ & $\mathrm{Al}_{2} \mathrm{O}_{3}$ & $\mathrm{Fe}_{2} \mathrm{O}_{3}$ & $\mathrm{MgO}$ & $\mathrm{SO}_{3}$ & $\mathrm{~K}_{2} \mathrm{O}$ \\
\hline & 63.21 & 21.91 & 5.2 & 3.64 & 2.02 & 2.21 & 1.04 \\
\hline \multirow{2}{*}{ Calcium hydroxide } & $\mathrm{CaO}$ & $\mathrm{SiO}_{2}$ & $\mathrm{MgO}$ & $\mathrm{Al}_{2} \mathrm{O}_{3}$ & $\mathrm{Fe}_{2} \mathrm{O}_{3}$ & LOI & \\
\hline & 71.9 & 1.42 & 2.97 & 0.64 & 0.3 & 21.5 & \\
\hline
\end{tabular}

The density of HSCSC is $2.93 \mathrm{~g} / \mathrm{cm}^{3}$, which is slightly lower than those of OPC $\left(3.15 \mathrm{~g} / \mathrm{cm}^{3}\right)$ and PBSC $\left(3.04 \mathrm{~g} / \mathrm{cm}^{3}\right)$. Its fineness is $6275 \mathrm{~cm}^{2} / \mathrm{g}$, which is higher than those of OPC $\left(3320 \mathrm{~cm}^{2} / \mathrm{g}\right)$ and PBSC $\left(4472 \mathrm{~cm}^{2} / \mathrm{g}\right)$. In addition, the initial setting time was $290 \mathrm{~min}$, and the final setting time was $525 \mathrm{~min}$, which was relatively longer than those of OPC and PBSC. Although the strength of HSCSC was similar to that of OPC at 28 days of age, the initial strength developed slowly. Table 5 lists the physical properties of OPC, PBSC, and HSCSC. 
Table 5. Physical properties of OPC, PBSC, HSCSC.

\begin{tabular}{cccccccc}
\hline \multirow{2}{*}{ Cement } & \multirow{2}{*}{ Density $\left(\mathbf{g} / \mathbf{c m}^{\mathbf{3}}\right)$} & \multirow{2}{*}{ Blain $\left(\mathbf{c m}^{2} / \mathbf{g}\right)$} & \multicolumn{3}{c}{ Setting Time (min) } & \multicolumn{3}{c}{ Compressive Strength (MPa) } \\
\cline { 3 - 8 } & & & Initial & Final & 3d & $\mathbf{7 d}$ & 28d \\
\hline OPC & 3.15 & 3320 & 200 & 310 & 20.3 & 33.1 & 44.9 \\
\hline PBSC & 3.04 & 4472 & 240 & 350 & 17.9 & 32.1 & 49.1 \\
\hline HSCSC & 2.93 & 6275 & 290 & 525 & 17.2 & 22.8 & 43.4 \\
\hline
\end{tabular}

\subsection{Evaluation of the Properties of HSCSC}

HSCSC uses approximately $80 \%$ blast furnace slag and, therefore, its environmental impacts are expected to be relatively low compared to those of PBSC, which has a granulated blast furnace slag content of 40-60\%, and OPC; however, it must primarily satisfy the basic properties required of cement. Therefore, to examine the basic properties of the HSCSC, the performance of the concrete that used HSCSC was compared with that of the concrete that used OPC or PBSC. For OPC, a product commonly used in South Korea was used, and, for PBSC, a product with a blast furnace slag content of $50 \%$ was used.

The performance of the concrete was analyzed through slump, air content, and compressive strength tests. The slump test was conducted in accordance with ISO 1920-2:2016 (Testing of concrete-Part 2: Properties of fresh concrete). The air content test was conducted in accordance with ISO 1920-2:2016 (Testing of concrete-Part 2: Properties of fresh concrete). The compressive strength test was conducted in accordance with ISO 1920-3:2019 (Testing of concrete-Part 3: Making and curing test specimens) and ISO 1920-4:2020 (Testing of concrete-Part 4: Strength of hardened concrete). The properties of the aggregates are presented in Table 6 . The density of the fine aggregate is $2.50 \mathrm{~g} / \mathrm{cm}^{3}$, the fineness modulus is 2.90 F.M, the absorption rate is $0.37 \%$, the unit volume weight is $1470 \mathrm{~kg} / \mathrm{cm}^{3}$, and the $0.08 \mathrm{~mm}$ sieve pass rate is $0.41 \%$. The density of the coarse aggregate is $2.64 \mathrm{~g} / \mathrm{cm}^{3}$, the fineness modulus is 7.07 F.M, the absorption rate is $0.56 \%$, the unit volume weight is $1525 \mathrm{~kg} / \mathrm{cm}^{3}$, and the $0.08 \mathrm{~mm}$ sieve pass rate is $0.40 \%$. The physical properties of OPC, PBSC, and HSCSC used in the tests are listed in Table 6. As the admixture, a carboxylic acid-based product having a solid content of $23 \%$ was used. The mixture design was performed for a unit binder content of $380 \mathrm{~kg} / \mathrm{m}^{3}$, and the concrete mixtures are listed in Table 7 . In this study, $0.8 \%$ superplasticizer was added to the binder.

Table 6. Physical properties of aggregate.

\begin{tabular}{|c|c|c|c|c|c|}
\hline Division & $\begin{array}{l}\text { Density } \\
\left(\mathrm{g} / \mathrm{cm}^{3}\right)\end{array}$ & $\begin{array}{c}\text { Fineness Modulus } \\
\text { (F.M) }\end{array}$ & Absorption Rate (\%) & $\begin{array}{c}\text { Unit Volume } \\
\text { Weight }\left(\mathrm{kg} / \mathrm{cm}^{3}\right)\end{array}$ & $\begin{array}{c}0.08 \mathrm{~mm} \text { Sieve Pass } \\
\text { Rate (\%) }\end{array}$ \\
\hline Fine aggregate & 2.50 & 2.90 & 0.37 & 1470 & 0.41 \\
\hline Coarse aggregate & 2.64 & 7.07 & 0.56 & 1525 & 0.40 \\
\hline
\end{tabular}

Table 7. Compositions of concretes.

\begin{tabular}{|c|c|c|c|c|c|c|c|c|c|}
\hline \multirow{2}{*}{ Specimen } & \multirow{2}{*}{$\begin{array}{l}\text { W/B } \\
(\%)\end{array}$} & \multirow{2}{*}{$\begin{array}{l}\text { S/a } \\
(\%)\end{array}$} & \multirow{2}{*}{$\begin{array}{c}\text { Water } \\
\left(\mathrm{kg} / \mathrm{m}^{3}\right)\end{array}$} & \multicolumn{3}{|c|}{ Binder $\left(\mathrm{kg} / \mathrm{m}^{3}\right)$} & \multicolumn{2}{|c|}{ Aggregate $\left(\mathrm{kg} / \mathrm{m}^{3}\right)$} & \multirow{2}{*}{$\begin{array}{c}\text { Ad. }\left(\mathrm{kg} / \mathrm{m}^{3}\right) \\
\text { Super Plasticizer }\end{array}$} \\
\hline & & & & OPC & PBSC & HSCSC & Sand & Gravel & \\
\hline OPC concrete & 50 & 45 & 190 & 380 & - & - & 832 & 918 & 3.04 \\
\hline PBSC concrete & 50 & 45 & 190 & - & 380 & - & 772 & 912 & 3.04 \\
\hline HSCSC concrete & 50 & 45 & 190 & - & - & 380 & 766 & 905 & 3.04 \\
\hline
\end{tabular}

The slump and air content were measured immediately after mixing the concrete, using a forced mixer. The compressive strength was measured at each age $(3,7$, and $28 \mathrm{~d})$. The compressive strength test was conducted in accordance with ISO 1920-4:2020 after preparing three $\Phi 100 \times 200 \mathrm{~mm}$ specimens by age and curing them in water at $20 \pm 2{ }^{\circ} \mathrm{C}$, in accordance with ISO 1920-3:2019. 


\subsection{Analysis of the Environmental Impacts of HSCSC}

To analyze the environmental impact of HSCSC, which is the primary focus of this study, the life cycle assessment (LCA) method, which systematically calculates the environmental impacts of a product during its life cycle, was utilized. To meet global standards, environmental impacts were calculated in accordance with ISO 14044:2006 (environmental management-life cycle assessment-requirements and guidelines) and the Product Environmental Footprint (PEF) Guide of the EU [20-22]. EU PEF is a system that formulates methods and procedures for calculating and communicating environmental information on products and services in accordance with ISO 14025:2006 (environmental labels and declarations-type III environmental declarations-principles and procedures) and ISO 14040:2006 (environmental management_LCA—principles and framework).

Environmental impacts were measured using a model that characterized impact categories in accordance with the PEF Guide. However, as HSCSC does not use biomaterials, the climate change (including biomaterials) category was excluded, and environmental impacts were calculated for the remaining 15 impact categories [23]. The GaBi LCA software was used to measure the environmental impact, which is the most widely used software for LCA evaluation, along with SimaPro. However, it is difficult to compare the measured category indicator results because each impact category uses different units. Therefore, normalization and weighting, the third and fourth steps in life cycle impact assessment, were performed to compare the category indicator results [24].

To objectively evaluate the environmental impacts of the three cement types, the functional unit, which is the evaluation criterion, was set to the "production of one ton of cement." The system boundary that determines the range of data collection includes the material and product production steps, as shown in Figure 1. The cut-off criteria were not set in the system boundary data, and all input and output data were collected. To evaluate the environmental impacts of HSCSC, the collected data included granulated blast furnace slag, calcium sulfate, OPC, and electricity.

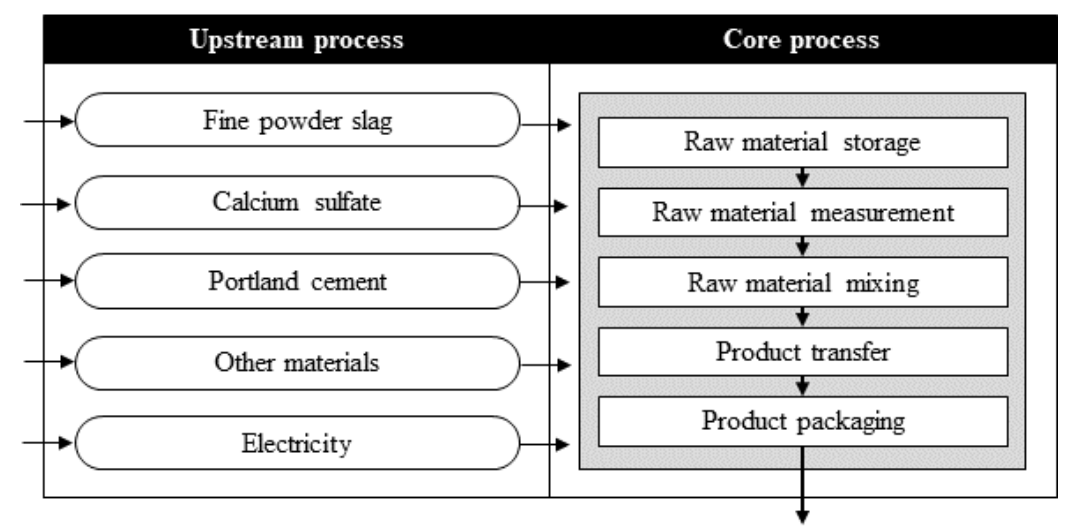

Figure 1. System boundary of HSCSC.

\section{Results and Discussion}

\subsection{Evaluation of the Properties of OPC, PBSC, and HSCSC Concrete}

HSCSC concrete was compared with OPC and PBSC concretes to determine whether it reduces the embodied energy of concrete and satisfies the basic properties of an eco-friendly binder. The results are as follows: the slump was $225 \mathrm{~mm}$ for OPC concrete, $190 \mathrm{~mm}$ for PBSC concrete, and $220 \mathrm{~mm}$ for HSCSC concrete, as shown in Figure 2. The measured air contents were similar with $4.4 \%, 4.1 \%$, and $4.3 \%$ for OPC, PBSC, and HSCSC concrete, respectively, as shown in Figure 3. 


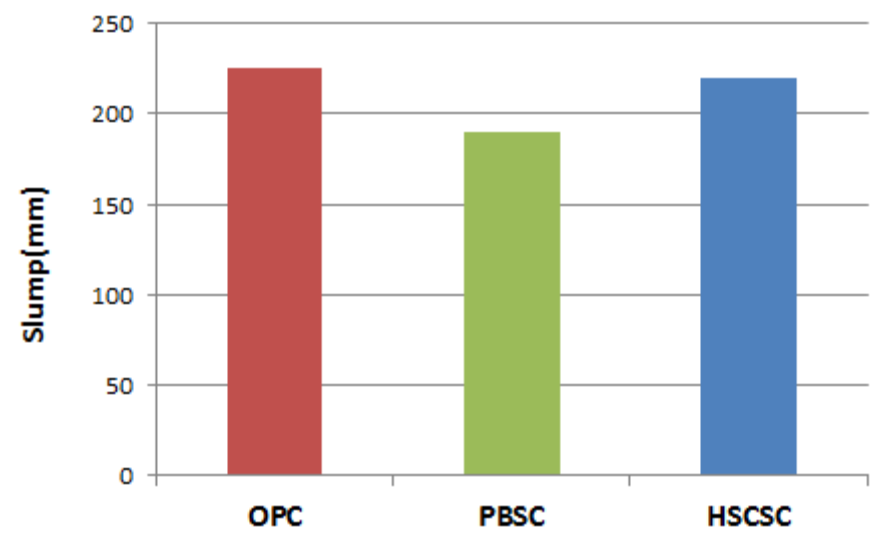

Figure 2. Slump of OPC, PBSC, and HSCSC concretes.

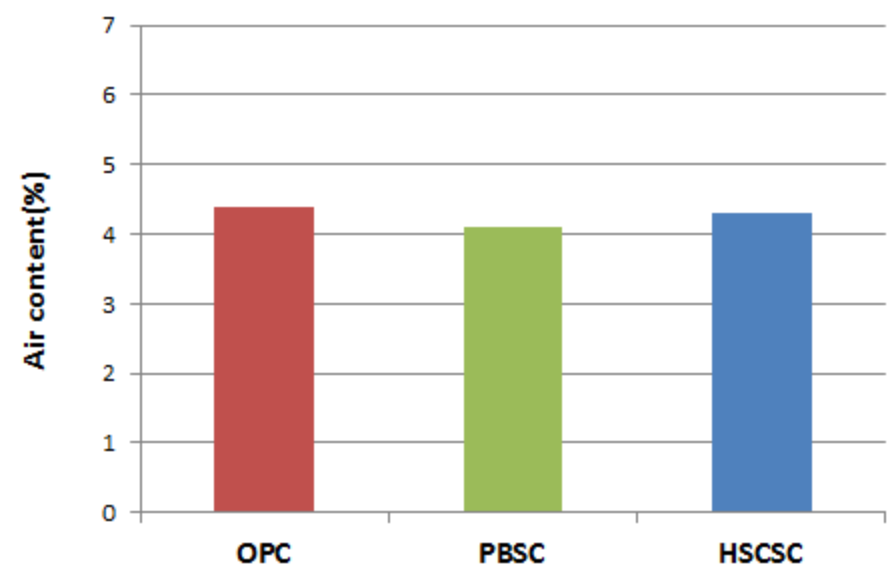

Figure 3. Air content of OPC, PBSC, and HSCSC concretes.

The results of the compressive strength measurement are shown in Figure 4 . At the ages of 3, 7, and 28 days, the strengths were 19.3, 26.5, and 37.8 MPa for OPC concrete; 16.7, 24.7, and 38.1 MPa for PBSC concrete; and 16.7, 22.8, and 36.2 MPa for HSCSC concrete, respectively. At the ages of 3 and 7 days, the compressive strength of OPC concrete was slightly higher, whereas those of PBSC and HSCSC concretes were similar. At the age of 28 days, the compressive strength of the PBSC concrete was slightly higher, whereas those of OPC and HSCSC concretes were similar.

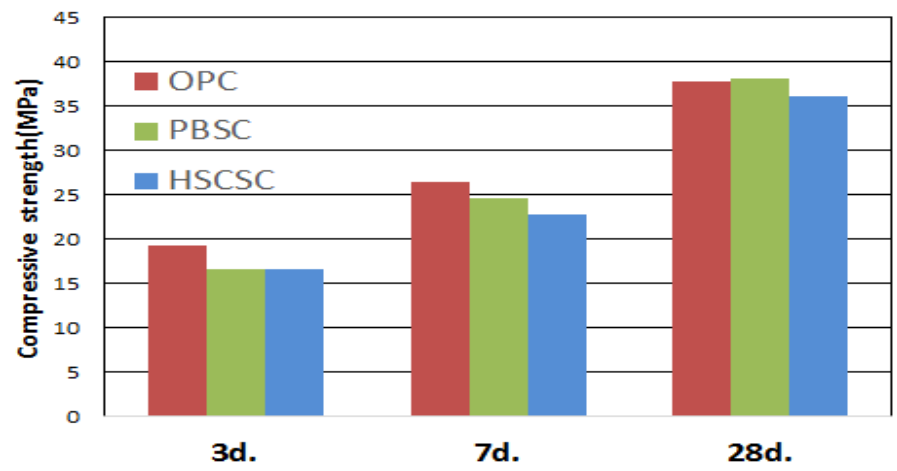

Figure 4. Compressive strength of OPC, PBSC, and HSCSC concretes.

The concrete comparison experiment results showed that the slump value of HSCSC concrete $(220 \mathrm{~mm})$ was similar to that of OPC concrete $(225 \mathrm{~mm})$. The air contents of the three concretes were very similar, indicating that OPC, PBSC, and HSCSC did not significantly affect the air content of concrete. At age of 28 days, the compressive strength 
of the HSCSC concrete (36.2 MPa) was similar to that of OPC concrete (37.8 MPa). Korean building codes require the compressive strength of general structural concrete to be $>18 \mathrm{MPa}$, and the compressive strength of concrete members that resist seismic force to be $>21 \mathrm{MPa}$. Considering these stipulations, HSCSC concrete is regarded as having sufficient rigidity as a general structural concrete, as HSCSC concrete satisfies the basic properties required of a concrete binder.

\subsection{Evaluation of the Environmental Impacts of OPC, PBSC, and HSCSC Concretes \\ 3.2.1. Environmental Footprint Analysis}

To examine the environmental footprint of the HSCSC, the environmental impacts of OPC and PBSC during the production of one ton of cement were compared and analyzed in accordance with ISO 14044:2006 and ISO 13315-8:2019 (Figure 5) [25]. For the objective analysis, the actual factory data were collected using questionnaires, and weighted averages were used for the production data of OPC and PBSC; the same environmental impact evaluation methodology and software as in the HSCSC analysis were used. The impact categories analyzed were acidification, climate change, ecotoxicity, eutrophication, marine eutrophication, terrestrial eutrophication, human toxicity (cancer), human toxicity (noncancer), ionizing radiation, land use, ozone depletion, particulate matter, photochemical ozone formation, resource depletion (water), and resource depletion (mineral).

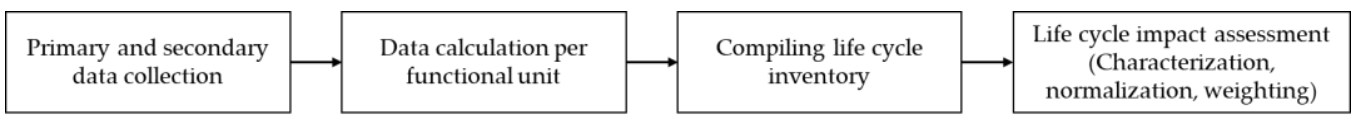

Figure 5. Procedure for measuring the environmental footprint of OPC and PBSC.

Table 8 summarizes the analysis results of 15 category indicators for the three cement types. Based on the results, the potential environmental impacts of HSCSC were significantly lower than those of OPC and PBSC in 14 impact categories, except for eutrophication in freshwater. Except for eutrophication freshwater, the results of HSCSC were 0.5 to $18.2 \%$ of OPC's. Its impact on resource depletion (mineral) was $0.5 \%$ of OPC's, and its impact on climate change was only $5.7 \%$ of OPC's. Its impact on human toxicity was only $6-15 \%$ of OPC's. However, its impact on eutrophication freshwater was $54 \%$ higher than that of OPC. This may be because the use of aluminum sulfate had a significant influence on eutrophication. Except for freshwater eutrophication and resource depletion (water), the results of HSCSC were 0.8 to $31.4 \%$ of PBSC's, which used $50 \%$ blast furnace slag, indicating no significant environmental impacts.

Table 8. Fifteen Category indicator results of three types of cements, including HSCSC.

\begin{tabular}{|c|c|c|c|c|c|c|c|}
\hline \multirow{2}{*}{ Impact Category } & \multirow{2}{*}{ Unit } & \multicolumn{2}{|c|}{ OPC } & \multicolumn{2}{|c|}{ PBSC } & \multicolumn{2}{|c|}{ HSCSC } \\
\hline & & Value (1) & $\%$ & Value (2) & $\%(2 / 1)$ & Value (3) & $\%(3 / 1)$ \\
\hline Acidification & Mole of $\mathrm{H}+\mathrm{eq}$. & $3.41 \times 10^{-3}$ & 100.0 & $1.68 \times 10^{-3}$ & 49.3 & $2.07 \times 10^{-4}$ & 6.1 \\
\hline Climate change & $\mathrm{kgCO}_{2}$ eq. & $1.20 \times 10^{1}$ & 100.0 & $5.26 \times 10^{-1}$ & 43.8 & $6.89 \times 10^{-2}$ & 5.7 \\
\hline Ecotoxicity & CTUe & $5.52 \times 10^{-2}$ & 100.0 & $3.59 \times 10^{-2}$ & 65.0 & $7.78 \times 10^{-3}$ & 14.1 \\
\hline Eutrophication freshwater & kg P eq. & $1.06 \times 10^{-6}$ & 100.0 & $4.47 \times 10^{-7}$ & 42.2 & $1.64 \times 10^{-6}$ & 154.7 \\
\hline Eutrophication marine & $\mathrm{kg} \mathrm{N}$ eq. & $3.71 \times 10^{-4}$ & 100.0 & $1.78 \times 10^{-4}$ & 48.0 & $3.44 \times 10^{-5}$ & 9.3 \\
\hline Eutrophication terrestrial & Mole of N eq. & $4.00 \times 10^{-3}$ & 100.0 & $1.92 \times 10^{-3}$ & 48.0 & $3.05 \times 10^{-4}$ & 7.6 \\
\hline Human toxicity (cancer) & CTUh & $9.91 \times 10^{-10}$ & 100.0 & $4.75 \times 10^{-10}$ & 47.9 & $1.49 \times 10^{-10}$ & 15.0 \\
\hline Human toxicity (non-cancer) & CTUh & $5.63 \times 10^{-8}$ & 100.0 & $2.44 \times 10^{-8}$ & 43.3 & $3.26 \times 10^{-9}$ & 5.8 \\
\hline Ionizing radiation & kBq U235 eq. & $6.51 \times 10^{-3}$ & 100.0 & $2.84 \times 10^{-3}$ & 43.6 & $4.31 \times 10^{-4}$ & 6.6 \\
\hline Land use & kg C deficit eq. & $2.28 \times 10^{-2}$ & 100.0 & $9.57 \times 10^{-3}$ & 42.0 & $2.29 \times 10^{-3}$ & 10.0 \\
\hline Ozone depletion & kg CFC-11 eq. & $3.30 \times 10^{-9}$ & 100.0 & $1.38 \times 10^{-9}$ & 41.8 & $1.49 \times 10^{-10}$ & 4.5 \\
\hline Particulate matter & kg PM2.5 eq. & $1.85 \times 10^{-4}$ & 100.0 & $9.04 \times 10^{-5}$ & 48.9 & $1.14 \times 10^{-5}$ & 6.2 \\
\hline Photochemical ozone formation & kg NMVOC eq. & $1.18 \times 10^{-3}$ & 100.0 & $5.67 \times 10^{-4}$ & 48.1 & $8.51 \times 10^{-5}$ & 7.2 \\
\hline Resource depletion (water) & $\mathrm{m}^{3}$ eq. & $2.34 \times 10^{-3}$ & 100.0 & $1.07 \times 10^{-3}$ & 45.7 & $4.27 \times 10^{-4}$ & 18.2 \\
\hline Resource depletion (mineral) & $\mathrm{kg} \mathrm{Sb} \mathrm{eq.}$ & $3.86 \times 10^{-7}$ & 100.0 & $2.62 \times 10^{-7}$ & 67.9 & $2.05 \times 10^{-9}$ & 0.5 \\
\hline
\end{tabular}




\subsubsection{Normalization and Weighting Analysis}

Comparing the category indicator results in Table 8 is difficult because the $15 \mathrm{impact}$ categories use different units. Therefore, the environmental impacts of the three cement types were normalized, thereby facilitating comparison by impact category. Table 9 presents the normalized results of the three cement types for the 15 impact categories. As shown in Equation (1), the normalized result of cement, $i$, for impact category, $j$, is obtained by dividing the category indicator results of impact category, $j$, by the normalized reference of the category.

$$
N R_{i j}=\frac{C R_{i j}}{\operatorname{NRef}_{i}}
$$

Table 9. Normalized results for 15 impact categories of three types of cements, including HSCSC.

\begin{tabular}{|c|c|c|c|c|c|c|c|}
\hline \multirow{3}{*}{ Impact Category } & \multicolumn{7}{|c|}{$\begin{array}{c}\text { Normalized Results } \\
\text { (Per Capita) }\end{array}$} \\
\hline & \multirow{2}{*}{$\begin{array}{l}\text { Normalized } \\
\text { Reference }\end{array}$} & \multicolumn{2}{|c|}{ OPC } & \multicolumn{2}{|c|}{ PBSC } & \multicolumn{2}{|c|}{ HSCSC } \\
\hline & & Value & Ranking & Value & Ranking & Value & Ranking \\
\hline Human toxicity (non-cancer) & $2.34 \times 10^{-4}$ & $2.41 \times 10^{-4}$ & 1 & $1.04 \times 10^{-4}$ & 1 & $1.39 \times 10^{-5}$ & 1 \\
\hline Climate change & $8.04 \times 10^{3}$ & $1.49 \times 10^{-4}$ & 2 & $6.54 \times 10^{-5}$ & 2 & $8.57 \times 10^{-6}$ & 2 \\
\hline Acidification & $5.56 \times 10$ & $6.13 \times 10^{-5}$ & 3 & $3.02 \times 10^{-5}$ & 3 & $3.72 \times 10^{-6}$ & 4 \\
\hline Human toxicity (cancer) & $1.86 \times 10^{-5}$ & $5.33 \times 10^{-5}$ & 4 & $2.55 \times 10^{-5}$ & 4 & $8.01 \times 10^{-6}$ & 3 \\
\hline Ionizing radiation & $1.38 \times 10^{2}$ & $4.72 \times 10^{-5}$ & 5 & $2.06 \times 10^{-5}$ & 6 & $3.12 \times 10^{-6}$ & 5 \\
\hline Particulate matter & $4.01 \times 10^{0}$ & $4.61 \times 10^{-5}$ & 6 & $2.25 \times 10^{-5}$ & 5 & $2.84 \times 10^{-6}$ & 6 \\
\hline Photochemical ozone formation & $4.07 \times 10$ & $2.90 \times 10^{-5}$ & 7 & $1.39 \times 10^{-5}$ & 7 & $2.09 \times 10^{-6}$ & 7 \\
\hline Eutrophication terrestrial & $1.77 \times 10^{2}$ & $2.26 \times 10^{-5}$ & 8 & $1.08 \times 10^{-5}$ & 8 & $1.72 \times 10^{-6}$ & 9 \\
\hline Eutrophication marine & $1.95 \times 10$ & $1.90 \times 10^{-5}$ & 9 & $9.13 \times 10^{-6}$ & 9 & $1.76 \times 10^{-6}$ & 8 \\
\hline Resource depletion (mineral, fossil) & $6.36 \times 10^{-2}$ & $6.07 \times 10^{-6}$ & 10 & $4.12 \times 10^{-6}$ & 10 & $3.22 \times 10^{-8}$ & 13 \\
\hline Ecotoxicity & $4.27 \times 10^{4}$ & $1.29 \times 10^{-6}$ & 11 & $8.41 \times 10^{-7}$ & 11 & $1.82 \times 10^{-7}$ & 11 \\
\hline Eutrophication freshwater & $1.61 \times 10^{0}$ & $6.58 \times 10^{-7}$ & 12 & $2.78 \times 10^{-7}$ & 12 & $1.02 \times 10^{-6}$ & 10 \\
\hline Land use & $7.48 \times 10^{4}$ & $3.05 \times 10^{-7}$ & 13 & $1.28 \times 10^{-7}$ & 13 & $3.06 \times 10^{-8}$ & 14 \\
\hline Resource depletion (water) & $1.15 \times 10^{4}$ & $2.03 \times 10^{-7}$ & 14 & $9.30 \times 10^{-8}$ & 14 & $3.71 \times 10^{-8}$ & 12 \\
\hline Ozone depletion & $4.84 \times 10^{-2}$ & $6.82 \times 10^{-8}$ & 15 & $2.85 \times 10^{-8}$ & 15 & $3.08 \times 10^{-9}$ & 15 \\
\hline
\end{tabular}

Here, NR stands for normalized results, $C R$ stands for category indicator results, and NRef stands for normalized reference. The unit of the normalized results is per person for all 15 impact categories. Therefore, the normalized result represents the environmental impact percentage generated in the life cycle of collecting resources and producing cement to produce one ton of cement compared to the average environmental impact generated by one person per year. Similar to the normalized reference used to obtain the normalized results, we used the global environmental footprint normalization factors [26] developed by the EU and based on the 2011 global population reported by the United Nations Department of Economic and Social Affairs (UNDESA New York, NY, USA).

Table 9 presents the normalized results of the three cement types for the 15 impact categories, along with the rankings. For all three cement types, human toxicity (non-cancer) and climate change were ranked first and second, whereas ozone depletion was ranked 15th, which is the lowest ranking. However, rankings from 3rd to 14th differed depending on the cement type. First, for the impact categories of normalized results of OPC, human toxicity (non-cancer) was ranked first, followed by climate change, acidification, human toxicity (cancer), ionizing radiation, particulate matter, photochemical ozone formation, terrestrial eutrophication, marine eutrophication, resource depletion (mineral and fossil), ecotoxicity, eutrophication of freshwater, land use, resource depletion (water), and ozone depletion. Although PBSC had rankings almost similar to those of OPC, ionizing radiation and particulate matter that were ranked fifth and sixth were switched. Contrastingly, the impact category rankings for HSCSC were different from those for OPC and PBSC. In particular, resource depletion (mineral and fossil) was ranked 10th for OPC and PBSC, whereas it was ranked 13th for HSCSC. This means that HSCSC consumes less fuel and mineral resources than OPC and PBSC. 
Table 10 lists the weighted results and eco-indices for the three cement types. The weighted results were obtained by considering the importance of environmental impacts by impact category as perceived by the general public to the quantitative analysis results derived through the normalization process, as shown in Table 9. In this study, the weighting factors developed by the European Commission (EC) Joint Research Center (JRC) for PEF evaluation were applied [27]. According to these, the weighting factor of climate change is 21.1, whereas that of human toxicity (non-cancer) is 1.84. This means that the general public considers the impact of climate change to be 11.4 times more important than the environmental impact caused by human toxicity (non-cancer). The weighted result of cement, $\mathrm{i}$, for impact category, $\mathrm{j}$, is obtained by multiplying the normalized result of impact category, $\mathrm{j}$, by the weighting factor of the category, as shown in Equation (2). Meanwhile, the eco-index for cement, $\mathrm{i}$, is the sum of the weighted results of cement, $i$, by impact category, $j$ :

$$
\mathrm{W} R_{i j}=N R_{i j} \times W F_{j} E I_{i}=\sum_{i=1}^{15} W R_{j}
$$

where $W R, W F$, and EI stand for weighted results, weighting factor, and eco-index, respectively.

Table 10. Weighted results for 15 impact categories of three types of cements, including HSCSC.

\begin{tabular}{|c|c|c|c|c|c|c|c|}
\hline \multirow{3}{*}{ Impact Category } & \multicolumn{7}{|c|}{$\begin{array}{l}\text { Weighted Results } \\
\text { (Per Capita) }\end{array}$} \\
\hline & \multirow{2}{*}{$\begin{array}{l}\text { Weighting } \\
\text { Factor }\end{array}$} & \multicolumn{2}{|c|}{ OPC } & \multicolumn{2}{|c|}{ PBSC } & \multicolumn{2}{|c|}{ HSCSC } \\
\hline & & Value & Ranking & Value & Ranking & Value & Ranking \\
\hline Climate Change & $2.11 \times 10$ & $3.14 \times 10^{-3}$ & 1 & $1.38 \times 10^{-3}$ & 1 & $1.80 \times 10^{-4}$ & 1 \\
\hline Human toxicity (non-cancer) & $1.84 \times 10^{0}$ & $4.43 \times 10^{-4}$ & 2 & $1.92 \times 10^{-4}$ & 3 & $2.56 \times 10^{-5}$ & 2 \\
\hline Particulate matter & $8.96 \times 10^{0}$ & $4.13 \times 10^{-4}$ & 3 & $2.02 \times 10^{-4}$ & 2 & $2.55 \times 10^{-5}$ & 3 \\
\hline Acidification & $6.20 \times 10^{0}$ & $3.80 \times 10^{-4}$ & 4 & $1.87 \times 10^{-4}$ & 4 & $2.31 \times 10^{-5}$ & 4 \\
\hline Ionizing radiation & $5.01 \times 10^{0}$ & $2.36 \times 10^{-4}$ & 5 & $1.03 \times 10^{-4}$ & 5 & $1.56 \times 10^{-5}$ & 6 \\
\hline Photochemical ozone formation & $4.78 \times 10^{0}$ & $1.39 \times 10^{-4}$ & 6 & $6.66 \times 10^{-5}$ & 6 & $9.99 \times 10^{-6}$ & 7 \\
\hline Human toxicity (cancer) & $2.13 \times 10^{0}$ & $1.13 \times 10^{-4}$ & 7 & $5.44 \times 10^{-5}$ & 7 & $1.71 \times 10^{-5}$ & 5 \\
\hline Eutrophication terrestrial & $3.71 \times 10^{0}$ & $8.38 \times 10^{-5}$ & 8 & $4.02 \times 10^{-5}$ & 8 & $6.39 \times 10^{-6}$ & 8 \\
\hline Eutrophication marine & $2.96 \times 10^{0}$ & $5.63 \times 10^{-5}$ & 9 & $2.70 \times 10^{-5}$ & 10 & $5.22 \times 10^{-6}$ & 9 \\
\hline Resource depletion (mineral, fossil) & $7.55 \times 10^{0}$ & $4.58 \times 10^{-5}$ & 10 & $3.11 \times 10^{-5}$ & 9 & $2.43 \times 10^{-7}$ & 14 \\
\hline Ecotoxicity & $1.92 \times 10^{0}$ & $2.48 \times 10^{-6}$ & 11 & $1.61 \times 10^{-6}$ & 11 & $3.50 \times 10^{-7}$ & 11 \\
\hline Land use & $7.94 \times 10^{0}$ & $2.42 \times 10^{-6}$ & 12 & $1.02 \times 10^{-6}$ & 12 & $2.43 \times 10^{-7}$ & 13 \\
\hline Eutrophication freshwater & $2.80 \times 10^{0}$ & $1.84 \times 10^{-6}$ & 13 & $7.77 \times 10^{-7}$ & 14 & $2.85 \times 10^{-6}$ & 10 \\
\hline Resource depletion (water) & $8.51 \times 10^{0}$ & $1.73 \times 10^{-6}$ & 14 & $7.92 \times 10^{-7}$ & 13 & $3.16 \times 10^{-7}$ & 12 \\
\hline Ozone depletion & $6.31 \times 10^{0}$ & $4.30 \times 10^{-7}$ & 15 & $1.80 \times 10^{-7}$ & 15 & $1.94 \times 10^{-8}$ & 15 \\
\hline Eco-index & & \multicolumn{2}{|c|}{$\begin{array}{c}5.06 \times 10^{-3} \\
(1618.7 \%)\end{array}$} & \multicolumn{2}{|c|}{$\begin{array}{c}2.29 \times 10^{-3} \\
(732.0 \%)\end{array}$} & \multicolumn{2}{|c|}{$\begin{array}{c}3.13 \times 10^{-4} \\
(100.0 \%)\end{array}$} \\
\hline
\end{tabular}

The weighted results in Table 10 show that climate change was ranked first for all three cement types. Climate change ranked second in the normalized results, which emerged as the largest environmental impact when social importance was considered. In the weighted results of OPC, climate change was ranked first, followed by human toxicity (non-cancer), particulate matter, and acidification. For PBSC, climate change was ranked first, followed by particulate matter, human toxicity (non-cancer), and acidification. Particulate matter, ranked fifth or sixth in the normalized results, was ranked second or third in the weighted results. For all three cement types, the impact category with the lowest ranking in the weighted results was ozone, similar to the normalized results. In the case of HSCSC, resource depletion (mineral) and land use impacts were evaluated to be the second and third lowest, respectively, unlike OPC and PBSC. Overall, climate change was ranked first, followed by human toxicity (non-cancer), particulate matter, and acidification, whereas ozone depletion had the lowest ranking, followed by resource depletion (mineral) and land use.

The eco-index of the HSCSC was $3.13 \times 10^{-4} \mathrm{PE}$, which means that the weighted result generated by $1 \mathrm{~kg}$ of HSCSC is $3.13 \times 10^{-4}$ times higher than that generated by one 
person for a year. The eco-indices of PBSC and OPC were 7.3 and 16.2 times higher than that of HSCSC, respectively. In other words, the eco-index of HSCSC was $13.7 \%$ and $6.2 \%$ of PBSC's and OPC's, respectively.

\subsubsection{Analysis of the Environmental Impacts of Major Impact Categories}

The analyses of weighted results of HSCSC for each impact category revealed that climate change was most significantly affected by HSCSC, followed by human toxicity (non-cancer) and particulate matter. The environmental impacts of these three impact categories were comprehensively analyzed. First, in the case of climate change, the carbon footprints of OPC, PBSC, and HSCSC were 1.2, 0.53 , and $0.07 \mathrm{kgCO}_{2} \mathrm{e}$, respectively. The carbon footprints of OPC and PBSC are 17.4 and 7.6 times higher than that of HSCSC, respectively (Figure 6). In other words, the carbon footprint of HSCSC is significantly low, as it is only $5.8 \%$ and $13.2 \%$ of OPC's and PBSC's, respectively, which apparently connotes that the use of HSCSC can considerably reduce carbon dioxide emissions by approximately $0.46-1.13 \mathrm{~kg} \mathrm{CO}_{2}$. As the global community, including South Korea, is looking for various methods for achieving net-zero in 2050, eco-friendly binders, such as HSCSC, can be considered as an excellent alternative to conventional cement, which causes considerable carbon dioxide emissions in certain areas.

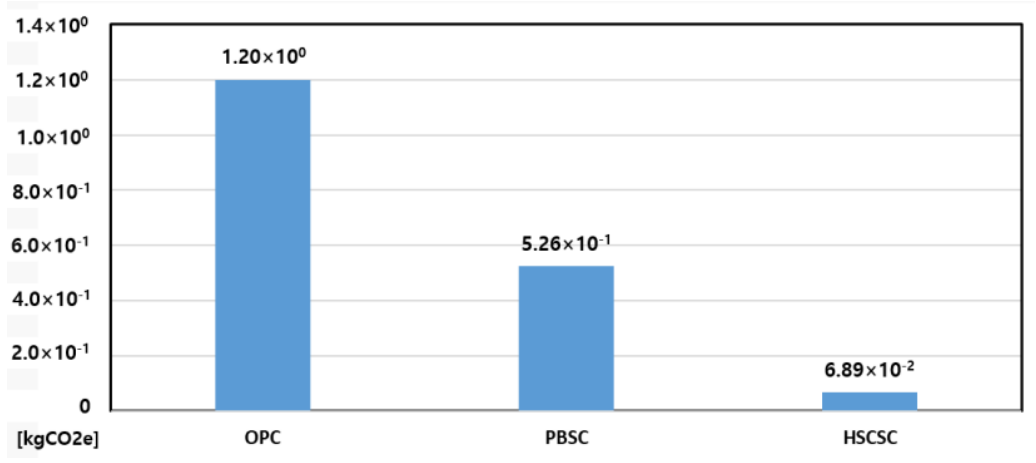

Figure 6. Comparison of carbon footprint of the three types of cements.

In the case of human toxicity (non-cancer), which exhibited the second largest weighted environmental impact, the impacts of OPC and PBSC were 7 and 17 times higher than that of HSCSC, respectively, as shown in Figure 7. The impact of HSCSC on human toxicity (non-cancer) is only 5.8 and $13.3 \%$ of OPC's and PBSC's, respectively. The Comparative Toxic Unit for humans (CTUh) is the unit of human toxicity, which represents the probability of causing a carcinogenic or non-carcinogenic impact. Therefore, the probability of HSCSC causing a non-carcinogenic impact on the human body can be interpreted to be only $5.8 \%$ and $13.3 \%$ of OPC's and PBSC's, respectively. These differences are mainly caused by the use of fuel. In addition, the probability of HSCSC causing a carcinogenic impact on the human body was found to be only 15.0, and $31.4 \%$ of OPC's and PBSC's, respectively.

Particulate matter, which represents the third largest weighted environmental impact, is also an environmental concern that has attracted considerable attention in South Korea due to climatic and geographic factors. The World Health Organization (WHO) also classified $\mathrm{PM}_{2.5}$ as a Group 1 carcinogen [24]. A comparison of the $\mathrm{PM}_{2.5}$ footprints of the three cement types is provided in Figure 8. As shown in the figure, the $\mathrm{PM}_{2.5}$ footprint of HSCSC is considerably low, representing only 6.2 and $12.6 \%$ of OPC's and PBSC's, respectively. When OPC or PBSC is replaced with HSCSC, $\mathrm{PM}_{2.5}$ can be reduced by 0.17 or $0.08 \mathrm{~g}$ per $1 \mathrm{~kg}$. Moreover, the impact of HSCSC on resource depletion (mineral) is only $0.5 \%$ and $0.8 \%$ of OPC's and PBSC's, respectively, which apparently improves the applicability of HSCSC as an eco-friendly binder. In conclusion, considering the impact of carbon dioxide emissions on climate change and other environmental impacts, it is ascertained that the HSCSC developed in this study is highly applicable as an eco-friendly binder that can reduce the embodied energy of concrete. 


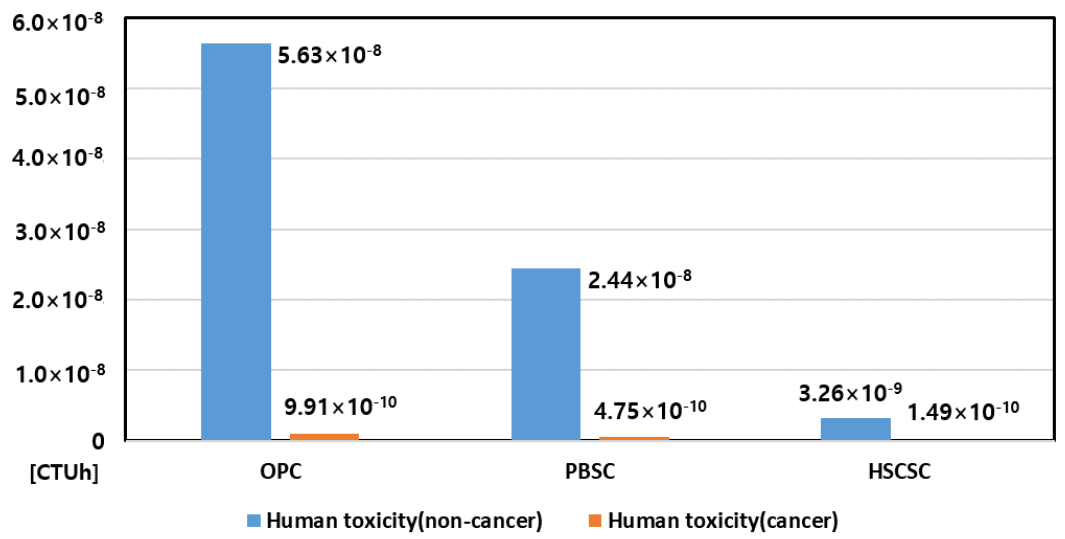

Figure 7. Comparison of human toxicities of three types of cements.

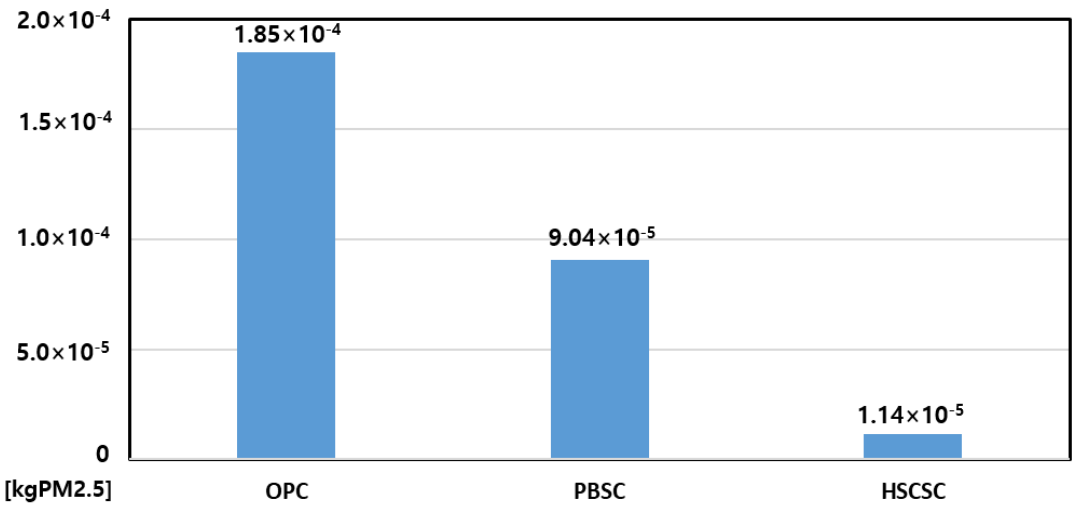

Figure 8. Comparison of particulate matter footprint of the three types of cements.

\section{Conclusions}

In this study, a new direction for the development of an eco-friendly cement that requires low embodied energy and has minimal environmental impacts is explored. The HSCSC developed here was found to satisfy the basic properties needed of an eco-friendly concrete binder. Our results suggest that it will be possible to commercialize this eco-friendly cement for use in general structures with the goal of producing ecological architecture.

We comprehensively analyzed the environmental impacts of OPC, PBSC, and HSCSC, and found the Eco-index of HSCSC to be $6.2 \%$ of OPC's and $13.7 \%$ of PBSC's. The carbon footprint of HSCSC is $5.8 \%$ and $13.3 \%$ of OPC's and PBSC's, respectively. These imply that non-negligible environmental benefits can be obtained from the practical use of HSCSC. The environmental impacts of HSCSC were significantly less than those of the other cements in 14 impact categories, though its impact on eutrophication was high. This pronounced eutrophication was due to the use of aluminum sulfate. A more precise analysis of the causal mechanism and improvements to the HSCSC will need to be established in future studies.

Author Contributions: Conceptualization and methodology, H.-S.K. and I.K. and W.-H.Y.; software, I.K.; validation, H.-S.K. and I.K. and W.-H.Y.; data curation, J.-Y.L. and S.-Y.M.; writing-original draft preparation, H.-S.K. and I.K. and W.-H.Y.; writing-review and editing, H.-S.K. and J.-Y.L. and S.-Y.M.; supervision, H.-S.K.; project administration, H.-S.K. All authors have read and agreed to the published version of the manuscript.

Funding: This study was supported by a grant [21AUDP-B146511-4] from the Architecture \& Urban Development Research Program funded by the Ministry of Land, Infrastructure and Transport of Korean government.

Institutional Review Board Statement: Not applicable. 
Informed Consent Statement: Not applicable.

Data Availability Statement: Not applicable.

Conflicts of Interest: The authors declare no conflict of interest.

\section{References}

1. Korea Energy Agency. Zero Energy Building Guide Verion 1; Korea Energy Agency: Ulsan, Korea, 2020.

2. Skalny, J.; Skalny, J.P.; Odler, I. Materials Science of Concrete: Calcium Hydroxide in Concrete; Wiley-Blackwell: Hoboken, NJ, USA, 2001.

3. Wagh, A.S. Chemically Bonded Phosphate Ceramics: Twenty-First Century Materials with Diverse Applications; Elsevier: Amsterdam, The Netherlands, 2016.

4. Roy, D.M. New strong cement materials: Chemically bonded ceramics. Science 1987, 235, 651-658. [CrossRef] [PubMed]

5. Provis, J.L.; Van Deventer, J.S.J. Geopolymers: Structures, Processing, Properties and Industrial Applications; Elsevier: Amsterdam, The Netherlands, 2009.

6. Davidovits, J. Geopolymer Chemistry and Applications, 3rd ed.; Davidovits, J., Ed.; Geopolymer Institute: Saint-Quentin, France, 2011.

7. Roy, D.M. Alkali-activated cements opportunities and challenges. Cem. Concr. Res. 1999, 29, 249-254. [CrossRef]

8. Shi, C.; Roy, D.; Krivenko, P. Alkali-Activated Cements and Concretes; CRC Press: Boca Raton, FL, USA, 2006.

9. Woltron, G. The Utilisation of GGBFS for Advanced Supersulfated. World Cement Magazine, 2009; 157-162.

10. POSCO Eco Report 4, 98\% Recycled Steel By-Products, How Are They Used, 2019. Available online: https://newsroom.posco. $\mathrm{com} / \mathrm{kr} / \% \mathrm{ED} \% 8 \mathrm{~F} \% \mathrm{AC} \% \mathrm{EC} \% 8 \mathrm{~A} \% \mathrm{A4} \% \mathrm{EC} \% \mathrm{BD} \% 94-\% \mathrm{EC} \% 97 \% 90 \% \mathrm{EC} \% \mathrm{BD} \% 94-\% \mathrm{~EB} \% \mathrm{A6} \% \mathrm{AC} \% \mathrm{ED} \% 8 \mathrm{~F} \% \mathrm{AC} \% \mathrm{ED} \% 8 \mathrm{~A} \% \mathrm{~B} 8$ -4/ (accessed on 21 December 2020).

11. BS EN 15743+ A1: 2015. Supersulfated Cement-Composition, Specifications and Conformity Criteria; British Standards Institution: Frankfurt am Main, Germany, 2015; Volume A1.

12. Hewlett, P.; Liska, M. Lea's Chemistry of Cement and Concrete; Butterworth-Heinemann: Oxford, UK, 2019.

13. Grounds, T.; Nowell, D.V.; Wilburn, F.W. The influence of temperature and different storage conditions on the stability of supersulphated cement. J. Therm. Anal. Calorim. 1994, 41, 687-699. [CrossRef]

14. Medellín, M.B.; Fuentes, A.; Gorokhovsky, A.; Escalante, J. Early and late hydration of supersulphated cements of blast furnace slag with fluorgypsum. Mater. Construcción 2015, 65. [CrossRef]

15. Rubert, S. Contribuição ao Estudo de Cimentos Supersulfatados: Formulação e Mecanismos de Hidratação; Universidade Tecnológica Federal do Paraná: Paraná, Brazil, 2015.

16. Gruskovnjak, A.; Lothenbach, B.; Holzer, L.; Figi, R.; Winnefeld, F. Hydration of alkali-activated slag: Comparison with ordinary Portland cement. Adv. Chem. Res. 2006, 18, 119-128. [CrossRef]

17. Haha, M.B.; Le Saout, G.; Winnefeld, F.; Lothenbach, B. Influence of activator type on hydration kinetics, hydrate assemblage and microstructural development of alkali activated blast-furnace slags. Cem. Concr. Res. 2011, 41, 301-310. [CrossRef]

18. Dutta, D.K.; Borthakur, P.C. Activation of low lime high alumina granulated blast furnace slag by anhydrite. Cem. Concr. Res. 1990, 20, 711-722. [CrossRef]

19. Bijen, J.; Niël, E. Supersulphated cement from blastfurnace slag and chemical gypsum available in the Netherlands and neighbouring countries. Cem. Concr. Res. 1981, 11, 307-322. [CrossRef]

20. ISO. ISO 14040 Environmental Management_Life Cycle Assessment_Principles and Framework; ISO: Geneva, Switzerland, 1997.

21. ISO. ISO 14044 Environmental Management_Life Cycle Assessment_Requirements and Guidelines; ISO: Geneva, Switzerland, 2006.

22. ISO. ISO 21930 Sustainability in Buildings and Civil Engineering Works-Core Rules for Environmental Product Declarations of Construction Products and Services; ISO: Geneva, Switzerland, 2017.

23. Francesco, C.; Antonio, F.; Ilenia, F.; Antonella, P. Life cycle assessment of different kinds of concrete containing wastes for sustainable construction. Buildings 2018, 8,70.

24. Manfredi, S.; Allacker, K.; Chomkhamsri, K.; Pelletier, N.; Souza, D.M. Product Environmental Footprint (PEF) Guide; European Commission: Brussels, Belgium, 2012.

25. ISO. ISO 13315-8 Environmental Management for Concrete and Concrete Structures-Part 8: Environmental Labels and Declarations; ISO: Geneva, Switzerland, 2019.

26. Serenella, S.; Eleonora, C.; Michela, S.; Rana, P. Global Normalization for the Environmental Footprint and Life Cycle Assessment; Publications Office of the European Union: Brussels, Belgium, 2017.

27. Sala, S.; Cerutti, A.K.; Pant, R. Development of a Weighting Approach for the Environmental Footprint; European Commission: Luxembourg, 2018. 